\title{
Trends in Soil Science Education and Employment
}

\section{J. Havlin*}

Dep. of Soil Science

North Carolina State Univ.

Raleigh, NC 27695

\section{N. Balster}

Dep. of Soil Science

Univ. of Wisconsin

Madison, WI 53706

\section{S. Chapman}

Soil Science Society of America

5585 Guilford Rd.

Madison, WI 53711

D. Ferris

School of Environmental and Natural Resources

Ohio State Univ.

Mansfield, OH 44906

\section{T. Thompson}

Dep. of Plant and Soil Science

Texas Tech Univ.

Lubbock, TX 79409

\section{T. Smith}

Dep. of Earth/Soil Sciences

California Polytechnic State Univ.

San Luis Obispo, CA 93407
During the last several decades, members of the SSSA have discussed several trends related to soil science education, including: (i) declining academic programs and course offerings at land grant universities, (ii) decreased enrollments, and (iii) improved employment opportunities for soil science graduates (SSSA, 2006; Ferris et al., 2010). The SSSA Advocacy/Education Task Force met in 2007 and concluded that quantitative survey information was needed to document trends in soil science academic programs, student enrollment, faculty, and job opportunities for graduates. Suggested survey topics included:
- Has the recognition of soil science as a distinct discipline increased or decreased?
- How has the job market changed during the past decade, and how will job opportunities for soil scientists change in the future?
- How have undergraduate and graduate soils curricula changed during the last decade?
- Has enrollment in soil science degree programs and courses changed during the past decade?
- Has there been a change in the degree programs of students enrolling in soils courses in the past decade?
. Have soil science programs been combined with other programs?

Therefore, the objective of the survey was to quantify trends in student enrollment, faculty positions, pertinent educational issues in soil and related sciences, and career or job opportunities and trends. Expected outcomes included a better understanding of current educational practices and trends, and identification of specific opportunities for SSSA to enhance the practice and profession of soil science.

\section{METHODOLOGY}

In 2008 the SSSA, in cooperation with the Social and Economic Sciences Research Center (SESRC) at Washington State University, conducted three surveys of (i) current undergraduate and graduate students enrolled in soils courses and recent graduates, (ii) academic departments offering soils courses and degrees, and (iii) employers hiring people with soils backgrounds. Student survey participants were identified from the SSSA student membership and were either currently or recently enrolled in soil science courses or in a soil science degree program. Academic departments were identified by SSSA and consisted of soils, agronomic, crop and plant, and environmental sciences departments in the United States and Canada. The employer survey participants were identified from SSSA membership and consisted of private and public industries, consulting firms, and government agencies in the United States who employ people with soil science backgrounds. The surveys were designed by the SSSA Task Force and SESRC, and reviewed by the SSSA Board of Directors. The questionnaires included both quantitative, categorical questions (i.e., strongly agree to strongly disagree) and open-ended response questions. The SESRC facilitated distribution of the web-based or hard-copy surveys to each group. Four e-mail reminders were sent to survey recipients to ensure a high response rate. Survey results were collected and summarized by the SESRC and interpreted by the SSSA Task Force. A complete report, as presented at the 2009 SSSA Annual Meeting, can be found at www.soils.org/files/aboutsociety/sssa-advocacy-survey-detailed-final-report-06302010.pdf (verified 22 July 2010).

Soil Sci. Soc. Am. J. 74:1429-1432

Published online 12 Aug. 2010

Open access article

doi:10.2136/sssaj2010.0143

This article has supplemental data available online.

Received 23 Mar. 2010.

*Corresponding author (havlin@ncsu.edu).

(C) Soil Science Society of America, 5585 Guilford Rd., Madison WI 53711 USA

All rights reserved. No part of this periodical may be reproduced or transmitted in any form or by any means, electronic or mechanical, including photocopying, recording, or any information storage and retrieval system, without permission in writing from the publisher. Permission for printing and for reprinting the material contained herein has been obtained by the publisher. 


\section{RESULTS AND DISCUSSION}

Among 2915 student survey recipients, 33\% completed or partially completed the web survey. The survey was also distributed to 245 departments and 1046 employers, with 63 and 42\% returned, respectively.

Survey responses provided interesting similarities and differences between the three survey groups. For example, differences in diversity between student and faculty populations were apparent, where the proportion of male and Caucasian faculty was higher than in the student population. Greater diversity in the student population may translate into improved diversity in future faculty.

Of the student respondents, the majority were graduate students $(81 \%)$, followed by undergraduates (18\%) currently enrolled in soil science or related majors such as agronomy and environmental science. Because of the dominance of graduate student respondents, the results may be somewhat skewed. For example, $82 \%$ of all students were very or somewhat interested in pursuing a career in soil science and $76 \%$ recommended soil science as a good career choice.

Similarly, when employed in a job directly or indirectly related to soil science, students would more likely (86 and 66\%, respectively) to seek future employment in a soil science profession. For students with no employment experience related to soil science, $86 \%$ indicated they would look for a job related to soil science following graduation. Although these results were probably influenced by the majority of graduate students in the survey group, a trend toward a priority in actively seeking soil science related positions can be seen.

The primary reasons students became interested in soil science courses or soil science as a discipline were related to classes or projects in college (39\%), previous work or agricultural experience (28\%), suggestion by a professor $(8 \%)$, or a class or project in or before high school (8\%). Moreover, the more coursework taken in soils or the longer the student was in a soil science major, the more they wanted to continue their education (and eventual employment) in soil science. Therefore, the primary method to increase the number of students enrolling in soil science would be to offer contemporary introductory soils courses that complement other majors and attract students with undeclared majors (Collins, 2008). The limited exposure to soil and related sciences in kindergarten through high school suggests that inclusion of soils and related topics in science curricula may enhance student interest in the soils discipline.

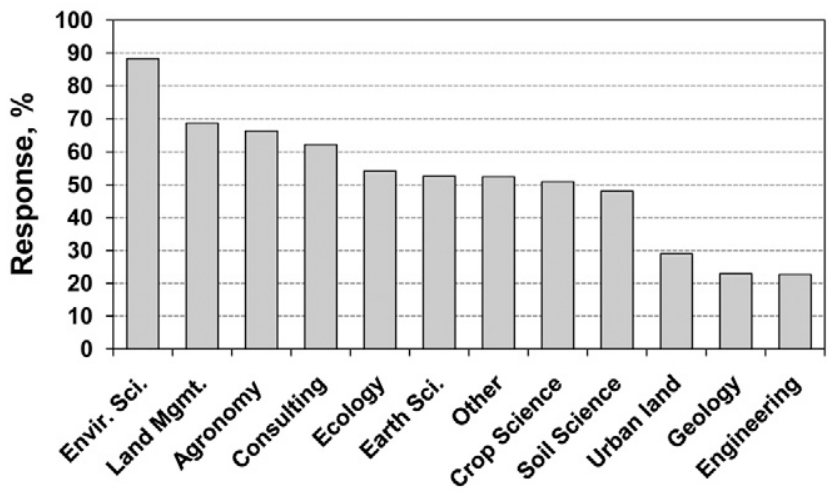

Fig. 1. Fields of employment that student respondents chose to pursue following graduation from college. Note that more than one could be chosen by each respondent. Options within the "other" category were not specified.
When student respondents were asked about specific fields of employment, environmental science received the highest endorsement, followed by land management, agronomy, consulting, ecology, and earth science fields (Fig. 1). Thus, students are largely interested in a variety of careers directly related to soil science, with many students interested in careers outside of traditional agriculture.

Although students displayed a positive attitude toward the soil science profession, consistent areas for improvement were communicated in the open-ended questions. The most frequent comments focused on the difficulty in locating job opportunities, enhancing the image of soil science and appreciation of soils in the natural world by the public, the need to better engage young minds in the soil science discipline, and the essential role of soil judging in soil science training. In addition, increased support for connecting graduates with employment opportunities is needed because the availability of job opportunities is the major factor influencing students' decision in choosing a major and will enhance recruitment of future students (Collins, 2008).

Departments are optimistic overall about the future of soil science. Many department responses indicated that student interest in the environment and sustainability is fueling increased student interest in soils. The majority of departments indicated that undergraduate and graduate enrollments in soil science courses have not changed during the past $10 \mathrm{yr}$; however, more departments thought enrollment in soil science courses would increase (69\%) in the next $10 \mathrm{yr}$ compared with decreases (56\%) in the past $10 \mathrm{yr}$.

Most departments indicated that student enrollment in soil science programs has not changed in the past $10 \mathrm{yr}$ and would probably not change in the next $10 \mathrm{yr}$. Of the department respondents, $41 \%$ indicated that enrollment had decreased during the past $10 \mathrm{yr}$, whereas only $15 \%$ indicated that enrollment had increased. In contrast, $28 \%$ predicted that enrollments would increase, while only $2.5 \%$ thought enrollments in soil science degree programs would decrease in the next $10 \mathrm{yr}$.

Although these data suggest that most departments thoink future enrollments in soil science will increase or stay the same relative to the previous $10 \mathrm{yr}$, students seem to foresee a decline in enrollment due to the identity of soil science being associated with agriculture. A majority of students surveyed felt that soil science as a discipline was suffering from an outdated linkage to agriculture and cited the need to emphasize an environmental focus. These data are consistent with the majority of future employment opportunities in environmental science as predicted by both students and employers.

Responding departments reported that they have not, in general, been losing soil science faculty positions in recent years. Most departments (53\%) indicated that soil science faculty full-time employment positions have not changed during the past $10 \mathrm{yr}$; however, $31 \% \mathrm{re-}$ ported decreases and $16 \%$ reported increases in full-time positions. Although most respondents (72\%) do not anticipate a loss of soil science full-time positions during the next $10 \mathrm{yr}, 17 \%$ anticipated a decrease and $11 \%$ anticipated an increase during the next $10 \mathrm{yr}$.

Most responding departments include soil science as part of a larger department, with an average and median of only 3.6 and 1.0 soils faculty full-time employment positions per department, respectively. Only $27 \%$ of the departments offer degrees in soil science even though soil science is often an important part of their curriculum. Thus, only a minority of 
departments are graduating degreed soil scientists. Fewer than $25 \%$ of soil science undergraduates participate in soil science internships. This should be of concern for departments and employers. Other data indicate that the ongoing economic recession and additional state budget cuts to higher education have further reduced faculty numbers on many campuses (The Chronicle of Higher Education, 2009).

Department respondents were generally optimistic about future prospects for soil science employment opportunities. Most departments (49\%) thought that job opportunities for soil science graduates had increased during the last $10 \mathrm{yr}$, while $40 \%$ indicated no change and $11 \%$ indicated that job opportunities had decreased. In contrast, fewer employers (37\%) thought job opportunities had increased during the last $10 \mathrm{yr}$, whereas $47 \%$ indicated no change and $16 \%$ indicated that job opportunities had decreased.

Although slightly more departments thought that student enrollments would increase than decrease during the next $10 \mathrm{yr}$, nearly $37 \%$ of employers thought it would be more difficult to find trained soil scientists, compared with only $7 \%$ who thought it would be easier to find qualified employees during the next 10 yr. Currently, 50\% of employers reported difficulty in finding qualified employees, where currently 21 and $29 \%$ found it less difficult or were neutral, respectively. The contrast between employer demand and department supply of trained soil scientists may indicate poor communication between departments and employers and warrants further study.

The suggested disconnect between departments and employers is supported by numerous comments by students, who suggested: (i) there are difficulties in finding job opportunities, and (ii) departments are not fully aware of potential job opportunities. Once students were employed or completed an internship in an organization that actually engaged in soils work, they were more likely to seek employment in soil science. These results provide a tremendous opportunity for departments, students, and employers to expand the field of soil science; however, improved communication between these groups is critical and consistently lacking, as evidenced by the results of this study.

Departments and employers generally agreed that environmental science presented graduates with the best future employment opportunities (Fig. 2). In contrast, employers thought there would be more job opportunities in agronomy than in land management and soil science, whereas departments thought the opposite.

Although most employers (79\%) thought that soil science education and training was adequate, there was some dissatisfaction with the abilities of graduates. Employers were asked to identify the most important soil science skill sets needed by their employees (Fig. 3). Respondents indicated that soil classification or survey, soil physical property or engineering assessment, and wetland soils were the three most important soil science skill sets. Employers consistently referred to the lack of field experience, in addition to poor communication (written and verbal) and critical thinking skills. Based on written comments, employers thought a lack of problem-solving skills reflected a lack of rigor or integration of knowledge within the curriculum. Specifically, employers emphasized enhanced field experiences in soil science including pedology and soil survey, site assessment, geographic positioning systems, and related areas.

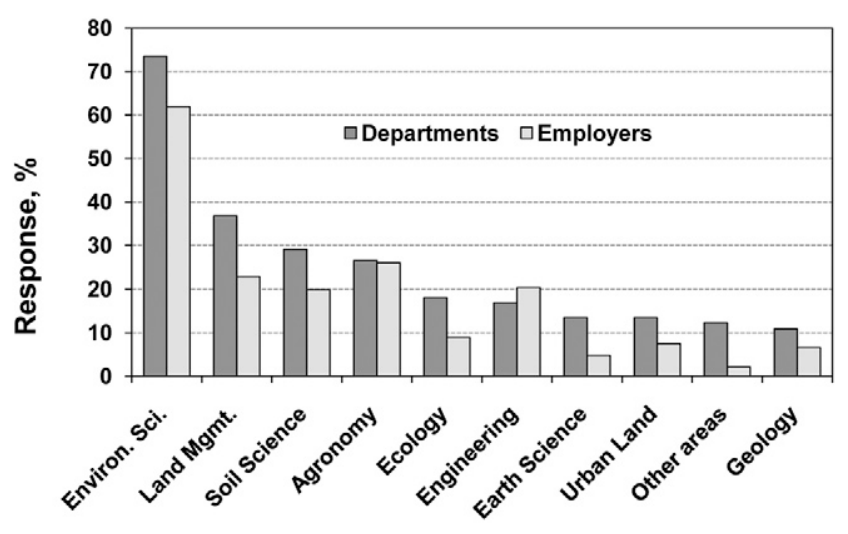

Fig. 2. Fields that offer the most future job opportunities for students with a degree or background in soil science. Data represent the sum of the top three rankings for the department and employer respondents.

Apparently, differences exist between academic departments and employers relative to soil science curriculum content. Several employers suggested that faculty and employers need to enhance communication relative to expected learning goals and outcomes, which is essential to academia providing quality employees to meet the needs of industry, and enhancing industry understanding and appreciation for the educational goals of an undergraduate or graduate education. One important opportunity to enhance student understanding of employer needs is to encourage and facilitate student membership in professional societies and to specifically organize industry-faculty communication sessions through SSSA annual meetings and through web-based programming.

Although not specifically addressed in the survey, a number of employer respondents suggested that there is a lack of respect for soil science among related professionals. Commonly, soil scientists compete with other professionals (engineers, geologists, etc.) in soil science related applications. Unfortunately, soil science may not be as recognized as engineering, geology, and related fields because each view soil science work as part of their responsibilities. Both professions require certification or licensing; however, these programs may be unknown or unused by soil scientists. In fact, several employers indicated there should be licensing or certification programs available to soil scientists. Therefore, it may be beneficial to enhance the marketing activities of current soil science certification and licensing programs.

Additional employer comments that should be addressed include soil science separation from the traditional agronomy image and en-

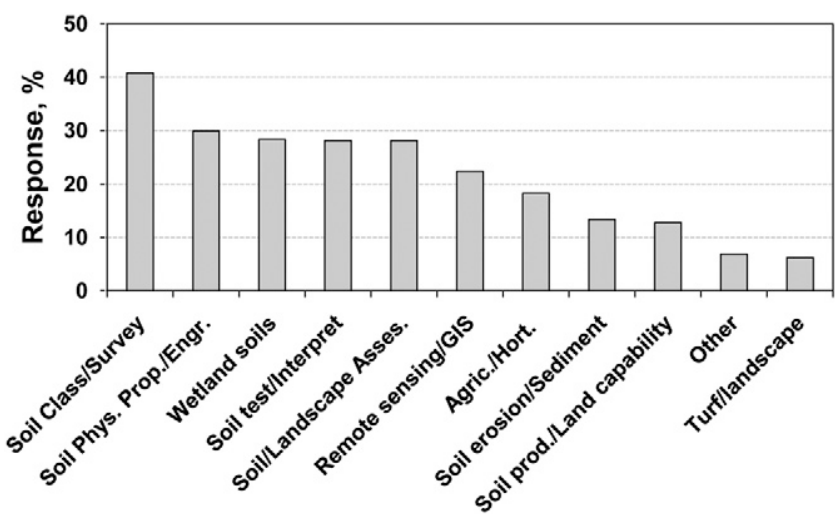

Fig. 3. Employer-identified soil science skill sets needed by employees. Data represent the sum of the top three rankings for each employer participant. 
hanced promotion of soil science. These barriers continue to concern employers, as indicated in their comments. Although licensing and certification are essential, SSSA and individual soil scientists need to continually promote the value of soil science to a diverse audience (Ferris et al., 2010).

\section{GENERAL RECOMMENDATIONS}

To address the concerns communicated by survey respondents, the SSSA should consider enhancing or initiating the following efforts:

1. The most important barrier to enhancing public understanding of the integrated science of soils is to comprehensively include soil properties, systems, and relationships to all other ecosystems in $\mathrm{K}-16$ education curricula, especially early undergraduate courses. Since 2005, the SSSA has had an established program to enhance soil science education; however, substantially more resources are needed to effect substantive changes in science curricula to include soils.

2. Similarly, the discipline of soil science needs to evaluate its image relative to agriculture and the environment. Although localized efforts are underway in this regard, the SSSA may need to assess its marketing at the national level relative to venues and groups unaware of the role of soil in the world. Because the perception of soils often varies even among soil science colleagues, marketing experts should be included in this effort.

3. To increase student enrollment in soil science, departments should evaluate the effectiveness of introductory courses to attract new majors (e.g., introductory courses in soils should be required for all environmental science majors), provide additional projects and internships to enhance student interest in soils, and market the major beyond agriculture at earlier stages in education (e.g., high school). The SSSA should encourage teaching faculty to develop and include a general soil and related science course in their curriculum open to any college student as part of their required general education science credits.

4. The SSSA should provide specific and direct communication to colleges and universities regarding future demand for trained scientists with a substantial background in soil science. Industry must collaborate with colleges and universities to substantially increase the number of internships and scholarships supporting student enrollment in soil-related sciences.
5. The SSSA should bolster communication between departments and students regarding job opportunities and internships. Students overwhelmingly cited a lack of communication relative to employment beyond college. This effort will require employers' direct assistance to departments so that such opportunities can be made known.

6. The SSSA should consider including in its strategic planning process the importance of producing trained soil-related scientists and practitioners with functional skills valued and needed by employers. Enhancing the soil science curriculum to ensure that students graduate with appropriate and functional field skills is urgently needed. Providing relevant departments with specific learning goals, objectives, and relevant curriculum materials, established in cooperation with industry partners, is essential.

7. Departments, employers, and students agreed that soil science professionals do not enjoy the same professional recognition as professionals in environmental science and engineering. The SSSA has had a certification program for nearly two decades; however, its efforts have not been sufficiently successful to enhance the professional status of soil scientists. The SSSA should reevaluate current certification programs and enhance assistance to states to enact licensing programs. To encourage certification and state licensing as a natural step in the career process, the SSSA should help facilitate certification programs and state licensing by integrating the fundamentals exam into soil science curricula.

Clearly, students, departments, and employers agree that soil science is a viable career path for diverse applications in environmental, agricultural, land resource, and related sciences. Although differences exist between student career interests and employer opportunities, enhanced promotion of soil science education and employment opportunities will advance soil science as a fundamental science integral to many related sciences.

\section{REFERENCES}

Collins, M.E. 2008. Where have all the soils students gone? J. Nat. Resour. Life Sci. Educ. 37:117-124.

Ferris, D.R., J.A. Hattey, and M.D. Mullen. 2010. Growing the soil science profession through investment, vestment and validation. Soil Sci. Soc. Am. J. 74:453-460.

The Chronicle of Higher Education. 2009. The Chronicle almanac of higher education 2009-10. Chronicle of Higher Education, North Hollywood, CA.

SSSA.2006. Th inking and planning strategically. Available at www.soils.org/ files/about-society/soils-2006-strategic-plan.pdf (verified 22 July 2010). SSSA, Madison, WI. 